\title{
Celso Furtado, intérprete da dependência
}

[ Celso Furtado, interpreter of dependency

\section{Rômulo Manzatto}

\section{Alexandre Macchione Saes ${ }^{2}$}

RESUMO - O artigo examina os usos e os sentidos da ideia de dependência no pensamento de Celso Furtado. Para isso, realizamos breve reconstituição do contexto em que as obras e as ideias do autor foram produzidas e acompanhamos as diferentes dimensões da interação entre subdesenvolvimento e dependência na trajetória de Furtado. - PALAVRAS-CHAVE - Celso Furtado; teoria da dependência; subdesenvolvimento. - ABSTRACT - The article examines the uses and meanings of the idea of dependency in Celso Furtado's thought. For this, we perform a brief reconstruction of the context in which the works and ideas are produced and follows the different dimensions of the interaction between underdevelopment and dependence in Furtado's trajectory. . KEYWORDS - Celso Furtado; dependence theory; underdevelopment.

Recebido em Iํ- de setembro de 2020

Aprovado em Io de fevereiro de $202 I$

MANZATTO, Rômulo; SAES, Alexandre Macchione. Celso Furtado, intérprete da dependência. Revista do Instituto de Estudos Brasileiros, Brasil, n. 78, p. I82-205, abr. 2021.

\section{(c) $(1) \Theta$}

DOI: https://doi.org/Io.II606/issn.23I6-90IX.vIi78pI82-205

I Universidade de São Paulo (USP, São Paulo, SP, Brasil).

2 Universidade de São Paulo (USP, São Paulo, SP, Brasil). 
Em entrevista realizada na década de I990, quando solicitado a compartilhar sua opinião sobre os significados da teoria da dependência, Celso Furtado parece ter acolhido a indagação com a naturalidade de quem considerava a ideia de dependência como um fato decorrente da estrutura do sistema econômico internacional e, portanto, um dado já amplamente reconhecido por todos os que como ele viviam desde sempre “dentro da teoria de centro-periferia" (BIDERMAN; COZAC; REGO, I996, p. 74).

Tanto a pergunta quanto a resposta de Furtado são carregadas de significados. Afinal, Celso Furtado foi um dos expoentes do estruturalismo latino-americano, uma escola de pensamento econômico criada na região entre as décadas de I940 e I950, e responsável por desenvolver uma interpretação original e amplamente difundida da trajetória de desenvolvimento econômico e social dos países da América Latina.

A teoria da dependência surgiria anos depois, em meados da década de I960. Em suas diferentes vertentes, os teóricos da dependência atacaram aspectos da visão estruturalista, propondo uma revisão crítica dessas ideias consolidadas outrora. Nessa nova orientação, os analistas da dependência procuraram ressaltar a necessidade de conferir maior ênfase aos condicionantes internos - analisando o papel desempenhado pelas classes sociais e sua interação dinâmica entre aspectos internos e externos -, assim como enfatizaram o sistema capitalista mundial a partir das formas de exploração imperialistas 3 .

Em todo caso, o estruturalismo latino-americano e a teoria da dependência constituíram as duas principais contribuições da América Latina para a história das ideias econômicas no século XX. É o que afirma, por exemplo, Joseph Love em sua reconstituição das ideias e ideologias econômicas da América Latina a partir de I930. Para Love o estruturalismo e a teoria da dependência foram capazes de romper com o padrão predominante na história das ideias na América Latina, até então restrita a descrever as adaptações regionais de ideias europeias. Diferente de suas predecessoras, essas novas contribuições surgiram como ideias autóctones, criações autênticas do pensamento local (LOVE, I996, p. 207).

Em orientação semelhante, Cristóbal Kay considera essas duas vertentes como

3 Para uma análise da teoria da dependência, cf.: Palma (I978), Mantega (I984, cap. 5), Love (I998, cap. I2), Sampaio Jr. (I999, cap. 2), Bresser Pereira (2010) e Kay (2018). 
as maiores contribuições surgidas na América Latina para a teoria crítica do desenvolvimento. Para Kay (20I8, p. 45I), o estruturalismo consistiu em importante contestação da teoria ortodoxa do comércio internacional, enquanto a teoria da dependência criticou de maneira incisiva as teorias da modernização em sua interpretação ortodoxa do fenômeno do subdesenvolvimento.

Nos dois casos, tanto o estruturalismo quanto a teoria da dependência têm em comum a proximidade com as atividades da Cepal, a Comissão Econômica para a América Latina. Também houve decisiva participação de Celso Furtado nos momentos iniciais de ambas as vertentes de pensamento4. Como lembra Ricardo Bielschowsky (200ob, p. 24-25; p. 4I-42), o contexto histórico em que se passam esses dois momentos é o da tentativa de compreensão dos elementos fundamentais do processo de industrialização da América Latina.

No primeiro momento, o de surgimento do estruturalismo, coube aos integrantes da Cepal a estruturação de um corpo teórico coerente, capaz de interpretar o intenso fenômeno da industrialização e da urbanização em curso na América Latina no período.

Fundada em I948 como órgão integrante da estrutura da Organização das Nações Unidas (ONU), a Cepal contou já em seus primeiros anos de existência com a atuação decisiva do economista argentino Raúl Prebisch na elaboração daquelas que viriam a ser as ideias-força, ou princípios, das atividades de pesquisa da Comissão nos anos seguintes. Furtado foi um dos primeiros integrantes do pequeno staff inicial da Cepal e fez parte do esforço pioneiro de consolidação e ampliação do corpo de ideias cepalinas, publicando Formação econômica do Brasil, que acabaria por se consolidar como obra basilar do estruturalismo latino-americano (BIESLCHOWSKY, 200ob, p. 20-22).

No segundo momento, em meados dos anos I960, a reflexão da teoria da dependência se voltou para a compreensão da frustração desse mesmo processo de industrialização, expressa na crise da industrialização por substituição de importações e na ascensão de governos autoritários nos países da região.

Em I964, também na sede da Cepal em Santiago do Chile, o mesmo Celso Furtado relata seu papel na organização de um ciclo de seminários voltados a uma reavaliação crítica da visão teórica produzida pela entidade a partir do início dos anos de I950. Nessa ocasião, coube a Furtado a apresentação de textos já clássicos do pensamento cepalino a um grupo de estudos que, a partir do dia 3 de junho de I964, passou a reunir-se para rediscutir o problema do subdesenvolvimento latino-americano tomando como base ideias formuladas na própria América Latina (FURTADO, 20I4, p. 4IO).

Por haver participado da redação de grande parte desses textos originais, de certa forma, os seminários consistiam também em uma reavaliação da produção intelectual de Furtado na última década como integrante do esforço teórico conjunto da Cepal em seu primeiro período de atuação. Entre os participantes do seminário, constavam antigos colaboradores da instituição, como o sociólogo José Medina Echavarría, assim

4 Francisco de Oliveira é um dos autores que reconhece a relação íntima existente entre a "teorização cepalino-furtadiana" e a teoria da dependência, mas, diferentemente de Joseph Love e Cristóbal Kay, considera a teoria da dependência como uma "sociologização menor" do pensamento de Furtado e da Cepal (OLIVEIRA, 2003, p. 80). 
como Fernando Henrique Cardoso e Osvaldo Sunkel, que viriam a se tornar dois dos mais relevantes autores ligados à crítica da economia política da Cepal.

Partindo da crítica ao estruturalismo, duas vertentes da teoria da dependência polarizaram o debate que se desenrola ao longo dos anos I970: uma defendendo a noção de um desenvolvimento desigual da economia mundial capitalista, por meio da apropriação das teses do imperialismo e tendo como formulador pioneiro o economista marxista André Gunder Frank5; outra alicerçada a partir da contribuição de Fernando Henrique Cardoso e Enzo Faletto, que, ao valorizar os determinantes sociais e políticos internos da industrialização periférica, viam a dependência como parte natural do processo de desenvolvimento do capitalismo contemporâneo.

Celso Furtado, instado a compreender a nova conjuntura econômica e política internacional, acabou formulando o que podemos chamar de uma terceira perspectiva da teoria da dependência ${ }^{6}$. Isto é, uma perspectiva radicalmente contrária à acepção da existência de desenvolvimento numa situação de dependência, como também contrária às teses marxistas, que àquela altura não mais encontravam condições para a realização de um projeto de desenvolvimento nacional. Sem recusar os alicerces fundamentais do estruturalismo latino-americano, o economista incorporou novos conceitos a suas reflexões e iluminou aspectos menos valorizados em suas análises pretéritas, aprofundando sua análise sobre o subdesenvolvimento.

$\mathrm{O}$ artigo pretende, desta forma, acompanhar os sentidos da ideia de dependência na obra de Celso Furtado, reiterando o pioneirismo e a densidade de sua contribuição para a teoria da dependência. Não obstante a contribuição de Furtado, o artigo buscar esclarecer como, entre as décadas de I950 e I970, houve um significativo refinamento de sua proposição sobre as condições de desenvolvimento nas economias subdesenvolvidas ao incorporar às suas teses a análise sociológica e cultural.

\section{DEPENDÊNCIA AVANT LA LETTRE?}

$\mathrm{Na}$ entrevista realizada em I990, ao responder à pergunta sobre a teoria da dependência, Furtado lembra que ele próprio havia escrito um livro abordando a temática, Uma economia dependente, publicado no ano de I956, portanto uma

5 Em outra orientação entre os marxistas, Theotônio dos Santos e Vânia Bambirra desempenharam papel de destaque no âmbito das teorias da dependência. Ver: Mantega ( I984, cap. 5), Bresser-Pereira ( 20Io) e Palma (I978). Uma comparação abrangente entre as concepções de subdesenvolvimento e dependência em Celso Furtado e Fernando Henrique Cardoso foi realizada por Almeida ( 2009). Recentemente, Brito ( 20I9) investigou o papel de Fernando Henrique Cardoso na análise da dependência, bem como sua interação com as ideias de Furtado e da Cepal, e Silva ( 2020) examinou a trajetória de Furtado na construção de uma interpretação própria da dependência.

6 Palma (I978, p. 898) defende a existência de três visões sobre a dependência, aproximando Furtado e Sunkel dessa terceira perspectiva, como uma reformulação da análise do desenvolvimento latino-americano produzida pela Cepal. Bresser-Pereira também destaca essa interpretação da qual Furtado seria o principal representante, denominada por Bresser como "nacional dependente” (PALMA, 20Io, p. 34). 
década antes que a teoria da dependência ganhasse repercussão no debate político e acadêmico (BIDERMAN; COZAC; REGO, I996, p. 74).

A questão guarda alguma controvérsia e comporta perspectivas conflitantes. O historiador Joseph Love, em linhas gerais, concorda com o pioneirismo de Celso Furtado na análise da dependência, chegando a afirmar que Furtado estaria em posição de "reivindicar o crédito de ter sido o primeiro analista da dependência" (LOVE, I998, p. 39I), mas parece discordar do economista brasileiro quanto ao fato de que essa contribuição analítica estaria presente já no livro de I956.

Para Love, tanto Uma economia dependente (I956) quanto Formação econômica do Brasil (I959) conteriam somente uma explicação estruturalista da trajetória do desenvolvimento brasileiro, mas ainda não contariam com os elementos necessários para caracterizá-las como precursoras da teoria da dependência. Em sentido estrito, ao analisar as obras de Furtado, Joseph Love compreende a teoria da dependência em suas primeiras manifestações como a identificação de um nexo causal entre o desenvolvimento dos países centrais e o subdesenvolvimento dos países periféricos. Ou seja, o historiador equivale a ideia de dependência à menção de que as trajetórias de crescimento de países ou regiões desenvolvidas constituem obstáculos diretos ao crescimento das regiões e dos países subdesenvolvidos (LOVE, I996, p. 252).

Nesse sentido, a ideia de dependência, para Joseph Love, teria sido mobilizada por Celso Furtado somente a partir de A Operação Nordeste (I959) e de Desenvolvimento e subdesenvolvimento (I96I). Publicados com dois anos de diferença, os textos têm finalidades bastante distintas. A Operação Nordeste era parte do curso "Introdução aos problemas do Brasil", ministrado aos oficiais das Forças Armadas brasileiras no Instituto Superior de Estudos Brasileiros (Iseb) em I959. O texto faz parte do esforço político de Furtado para a criação da Sudene, a Superintendência do Desenvolvimento do Nordeste, que propunha uma nova abordagem para atacar as desigualdades regionais do processo de desenvolvimento brasileiro então em curso.

$\mathrm{Na}$ ocasião, Furtado procurou sintetizar a questão ao explicar que o processo de desenvolvimento econômico do Brasil nas décadas anteriores havia avançado no sentido de uma maior articulação entre as diferentes regiões do país, tendo como centro gravitacional do processo a região centro-sul, que se desenvolvia impulsionada externamente pelas exportações de café. A questão, para Furtado ([I959] 2009, p. 3I), é que esse tipo de desenvolvimento ocorria a partir da reprodução do "mesmo esquema de divisão geográfica do trabalho que viciaria todo o desenvolvimento da economia mundial, com suas metrópoles industrializadas e colônias produtoras de matérias-primas".

Para Furtado ([I959] 2009, p. 32), o desenvolvimento industrial da região centro-sul do Brasil havia ocorrido a partir da subordinação das outras regiões, agora tornando patentes as "relações de dependência" entre esse novo centro industrial e as demais regiões brasileiras produtoras de matérias-primas.

Os trechos que parecem ter chamado a atenção de Joseph Love em A Operação Nordeste são aqueles em que Furtado afirma que "as relações econômicas entre uma economia industrial e economias primárias tendem sempre a formas de exploração" e em que deduz as consequências desse tipo de relação, destacando uma "tendência das economias industriais [...] a inibir o crescimento das economias primárias" 
(FURTADO, [I959] 2009, p. 32), fenômeno que estaria sendo reproduzido internamente no Brasil. Conclui Love (I998, p. 386): "Em seus dois estudos regionais de I959 [...], Furtado já havia percebido a relação que ele, Osvaldo Sunkel, Fernando Henrique Cardoso e André Gunder Frank viriam a desenvolver em meados da década de I960".

A obra Desenvolvimento e subdesenvolvimento, por sua vez, lida com uma temática mais ampla e pode ser considerada como uma síntese das ideias de Furtado sobre desenvolvimento na década de I950 (SZMRECSÁNYI, 200I, p. 347). Dessa obra, Joseph Love seleciona um trecho de "Elementos de uma teoria do subdesenvolvimento", em que Furtado reconstitui o surgimento do que chama de "estruturas subdesenvolvidas" a partir dos diferentes momentos de expansão da economia industrial europeia7.

Em perspectiva histórica, Furtado registra o surgimento de um poderoso e dinâmico núcleo industrial na Europa no século XVIII, que teria passado a "condicionar o desenvolvimento econômico subsequente em quase todas as regiões da terra" (FURTADO, I96I, p. I78).

Em suas duas fases de expansão, explica Furtado (I96I, p. I79), a economia industrial europeia primeiro "desorganizou a economia artesanal pré-capitalista pela progressiva absorção de fatores liberados a um nível mais alto de produtividade" e depois deslocou-se para "onde quer que houvesse terras ainda desocupadas e de características similares às da própria Europa”. Estavam postas as bases da posterior colonização da Austrália, do Canadá e dos Estados Unidos, com estruturas que Furtado (I96I, p. I79-I80) considerou como "simples prolongamentos da economia industrial europeia”, em função mesmo de suas semelhanças com as estruturas econômicas da Europa ocidental.

No terceiro momento, essa expansão da economia industrial europeia se voltou para outras regiões, já "densamente povoadas, com seus sistemas econômicos seculares, de variados tipos, mas todos de natureza pré-capitalista” (FURTADO, I96I, p. I7I). Dessa longa interação, surgiriam "estruturas híbridas, uma parte das quais tendia a comportar-se como um sistema capitalista, a outra, a manter-se dentro da estrutura preexistente" (FURTADO, I96I, p. I80), formando o tipo de estrutura dualista que, para Furtado, constituiria o fenômeno então contemporâneo do subdesenvolvimento.

O que leva Furtado (I96I, p. I80) à célebre conclusão de que "o subdesenvolvimento é, portanto, um processo histórico autônomo, e não uma etapa pela qual tenham necessariamente, passado as economias que já alcançaram grau superior de desenvolvimento". Assim, para Joseph Love, esses seriam finalmente os elementos responsáveis por fazer de Celso Furtado um dos precursores da teoria da dependência. O que não esgota a questão.

Em sentido amplo, Ricardo Bielschowsky localiza as primeiras manifestações da teoria da dependência em período anterior ao considerado por Love. Bielscho

7 No capítulo 2, “O mecanismo do desenvolvimento", Furtado faz o contraste entre "economias desenvolvidas e subdesenvolvidas" e "economias autônomas e dependentes", sem nenhuma preocupação maior de diferenciar os conceitos. As expressões são usadas pelo autor enquanto fala sobre a "taxa de capitalização", indicando a impossibilidade de transferir os modelos de análises de países desenvolvidos para subdesenvolvidos (FURTADO, I96I, p. IO0). 
wsky (2000, p. 42)considera que a ideia de "dependência”, em seus sentidos financeiro, comercial e tecnológico, "esteve presente na Cepal, desde as suas origens, ainda que a expressão propriamente dita não fosse utilizada”.

Nesse sentido, observa-se que em Uma economia dependente, livro a que se refere Furtado na entrevista, o termo dependente é propriamente utilizado em mais de uma ocasião, de maneira a enfatizar o sentido da dependência financeira de uma economia majoritariamente exportadora de produtos primários. É nessa acepção que, no segundo capítulo da obra, Furtado (I956, p. 24) faz uso do termo economia dependente para caracterizar a economia do café brasileira como "primárias-dependentes", sendo "exportadora de capitais em épocas de depressão".

Já o sentido tecnológico da dependência seria abordado em A economia brasileira, primeira obra de teoria econômica de Furtado, publicada em I954. Na ocasião, o economista ressaltou a importância da assimilação de técnicas de produção e conhecimentos científicos estabelecidos nas economias desenvolvidas e chamou a atenção para o fato de que, nos países subdesenvolvidos, a deficiente utilização desses fatores de produção se devia à escassez do fator capital: "desperdiça-se um fator - mão de obra - porque o outro é insuficiente - capital” (FURTADO, I954, p. I94)9.

Somente em versão posterior desse mesmo texto, publicada em Desenvolvimento e subdesenvolvimento, é que Furtado avança o raciocínio e parece extrair todas as consequências do efeito da diferença de tecnologias e técnicas entre países desenvolvidos e subdesenvolvidos. No livro de I96I, Furtado procura ressaltar o contexto histórico de surgimento das tecnologias de produção. No caso clássico de industrialização, o da economia inglesa, o desenvolvimento dessas tecnologias ocorreu, em uma primeira fase, em um contexto de uso intensivo do fator trabalho, que era liberado a partir da desarticulação da economia artesanal. Somente quando praticamente toda a mão de obra então disponível foi absorvida é que esse desenvolvimento tecnológico se voltou para o aumento do grau de mecanização, visando deter a tendência de alta nos salários pela substituição da mão de obra (FURTADO, I96I, p. I63-I77).

Já o sentido comercial da dependência é abordado por Furtado na obra de I956, em que o autor destaca o esforço organizado dos cafeicultores brasileiros na articulação de um mecanismo de valorização do preço de seu produto nos mercados internacionais, o que levaria à instituição de uma longeva política de formação interna de estoques de café, visando a maior controle sobre a flutuação dos preços do artigo, bem como de suas condições de venda, o que acabaria por estabelecer uma situação privilegiada aos cafeicultores brasileiros no comércio internacional (FURTADO, I956, p. 4I-42).

8 Bielschowsky (200ob, p. 3I), no intuito de mostrar a coerência analítica da Cepal, entende que o argumento da vulnerabilidade externa, tese central da instituição, acompanhou as cinco décadas de reflexão de seus economistas, mas ganhando na década de I960 a denominação de "dependência financeira e tecnológica" e na década de I970 a de "enriquecimento analítico da "dependência”, por meio do exame do papel das transnacionais nas economias periféricas.

9 Versão anterior desse texto é encontrada em artigo de I952 em que Furtado comenta as conferências de Ragnar Nurkse no Brasil (FURTADO, I952, p. I5). 
Ocorre que as falhas e desvantagens dessa política de valorização não demoraram a se manifestar. A elevação artificial do preço do café aumentava também artificialmente a rentabilidade dessa atividade, estimulando o aumento da produção acima do que o mercado internacional era capaz de absorver. Adicionalmente, lembra Furtado, não foram levadas em conta as "características próprias de uma atividade econômica de natureza tipicamente dependente como era a produção de café no Brasil" (I956, p. 44), que avançaria internamente até que todos os fatores de produção disponíveis fossem esgotados, ou até que o mercado internacional estivesse saturado.

Isto é, mesmo o mecanismo de sustentação de preços do café não poderia mitigar a tendência de longo prazo de deterioração relativa dos preços do café, segundo o economista. Não bastasse, ao sustentar as cotações internacionais do produto, o Brasil fomentava a produção de países concorrentes, além do considerável esforço financeiro que o financiamento das compras de estoques impunha à economia do país. Assim, uma política que nascera com o intuito de mitigar a dependência do país quanto às oscilações de mercado de seu principal produto de exportação acabou por acarretar efeitos negativos de longo prazo, precipitando e aprofundando a crise do "sistema de economia dependente no Brasil" (FURTADO, I956, p. 45).

Os efeitos e as consequências da política de valorização do café se fizeram sentir de maneira mais aguda na crise de I929. A queda do preço do produto nos mercados internacionais, somada à súbita desvalorização cambial, à dificuldade de financiamento externo e ao já considerável volume imobilizado de estoques, colocou em posição difícil os exportadores brasileiros. A resposta encontrada foi a de intensificar a política de compra de estoques de café a ponto de parte expressiva do café acumulado ter de ser queimado ou destruído para evitar uma pressão sobre os preços futuros do café. Essa ação acabou por agir como o equivalente a uma política anticíclica de sustentação do nível da demanda interna e contribuiu para a manutenção do nível de emprego da economia brasileira no período de crise, segundo Furtado.

Sobre esse episódio, já décadas mais tarde, em seminário acadêmico realizado em setembro de I980 na cidade do Rio de Janeiro, Furtado rememorou uma conversa com Osvaldo Aranha, então membro do governo Vargas, responsável pela política de queima do café. Conta Furtado que Osvaldo Aranha deixou claro que essas ações não foram tomadas como parte de um projeto ou plano econômico estruturado, mas sim como respostas quase desesperadas às consequências da crise econômica de I929. A ponto de Aranha então declarar, segundo Furtado, que só havia entendido o sentido dessas políticas econômicas após conhecer a explicação do economista em Formação econômica do Brasil (FURTADO, I983, p. 7I7).

Nesse esforço para garantir a sobrevivência da economia brasileira, houve audácia política e ação guiada para além dos dogmas da política econômica ortodoxa, acreditava Furtado, para quem as elites da época foram capazes de conceber soluções em desacordo com o que pregavam as ideias estabelecidas no pensamento e na prática econômica. Mesmo a reflexão sobre a consciência política e os interesses das elites locais já em alguma medida figurava nos trabalhos de Furtado na década de I950. Em Formação econômica do Brasil, o economista já chamava a atenção para as diferenças na formação e nas características das classes dirigentes da economia do açúcar e do café no Brasil. 
As elites do açúcar teriam se formado imersas em uma atividade econômica cujos dirigentes de fato, os que tomavam as decisões fundamentais do negócio, estavam situados em Portugal ou na Holanda. De modo que, isolados no Brasil, os dirigentes locais "não puderam desenvolver uma consciência clara de seus próprios interesses" (FURTADO, [I959] 2007, p. I7I).

$\mathrm{Na}$ economia do café o processo foi distinto. Essa nova classe dirigente agiu para controlar todas as fases da produção e do comércio do café, gestando uma elite dirigente que se diferenciava de outros grupos dominantes do passado por ter agora uma "consciência clara de seus próprios interesses" (FURTADO, [I959] 2007, p. I72).

A mesma orientação aparece em obras de Furtado mais voltadas para o diálogo com o seu próprio contexto político. Em A pré-revolução brasileira (I962), publicado no mesmo ano em que Furtado assume o posto de ministro do Planejamento, é claro o entusiasmo do economista com as possibilidades abertas pela "conquista dos centros de decisão", em que a economia brasileira não mais seria comandada "de fora para dentro", tampouco forçada a seguir “os ziguezagues de um destino de povo dependente" (FURTADO, I962, p. II5).

O reconhecimento do papel político na definição dos usos dos recursos gerados pelas exportações, todavia, ainda é insuficiente para admitir que Furtado já estivesse adiantando seus próprios argumentos sobre o sentido de dependência ${ }^{\mathrm{IO}}$. O projeto político do autor naquela oportunidade defendia a atuação do Estado no sentido de definir, por meio do planejamento, as prioridades do país para ampliar a poupança que viabilizasse o investimento industrial (FURTADO, I958). Uma política de elevação das exportações, de estímulos para a elevação da produtividade do trabalhador e de ruptura com os gastos supérfluos resultantes do "efeito demonstração", que liquidava com os limitados recursos para os investimentos numa política de desenvolvimento. Em suma, mesmo que a crítica sobre o padrão de consumo das elites já estivesse presente em sua análise - argumento comum ao debate dos anos I950 -, a leitura enfatizava a fragilidade do balanço de pagamentos de uma economia periférica, isto é, voltava os olhos para o caráter reflexo da economia subdesenvolvida no comércio internacional ${ }^{\text {II }}$.

A dimensão de dependência escrutinada na obra de Furtado até I964, portanto, revela um sentido ainda bastante próximo das teses estruturalistas da Cepal, de uma periferia em posição subordinada no sistema capitalista internacional, dependente de capital e de tecnologia. A aposta na industrialização como formadora do sistema econômico era ainda a aposta para a superação da condição de dependência, isto é, do subdesenvolvimento. Todavia, o entendimento de que as teses da dependência já

Io Em Desenvolvimento e subdesenvolvimento o autor valoriza a conquista dos centros de decisão que se apoiavam nas indústrias em contraposição aos grupos ligados ao setor externo, "par excellence grupos dependentes”. A afirmação da mentalidade “desenvolvimentista” permitia a concentração dos escassos recursos do país para uma política industrial e nacional, isto é, encontrando a racionalidade do planejamento cepalino como instrumento de superação do subdesenvolvimento (FURTADO, I96I, p. 2I5).

II A discussão sobre as condições de superação do desenvolvimento ganhou importante relevância para Furtado a partir de seu debate com Ragnar Nurkse, autor que desenvolveria o conceito de efeito demonstração como emulação do padrão de consumo por parte das elites dos países subdesenvolvidos (LOVE, I998, p. 369-370). 
estavam presentes desde suas formulações dos anos I950, como sugere o autor em Conversas com economistas (BIDERMAN; COZAC; REGO, I996) ou mesmo em Os ares do mundo, tende a dar maior coerência e continuidade à sua trajetória do que a história de suas ideias econômicas parece indicar ${ }^{\mathrm{I2}}$. Em suma, o estruturalismo cepalino era necessário, mas não suficiente para apreender a dimensão política e social que a teoria da dependência absorveria.

Pouco tempo depois, a crise da industrialização por substituição de importações e a crise política no Brasil colocariam à prova as ideias da Cepal e de Furtado dos anos I950. A ascensão dos governos militares em toda a América Latina acelerou o processo de crítica das interpretações do desenvolvimento latino-americano da década de I950, passando-se então a uma visão bem menos otimista, com maior ênfase em pensar os obstáculos políticos e o papel das elites nacionais na manutenção da situação de dependência da região. Como sugerimos a seguir, a incorporação do sentido de dependência em Celso Furtado deve ser entendida como uma ruptura em sua trajetória intelectual, desenvolvida a partir de seu exílio, que produziria uma interpretação renovada e mais ampla sobre o sentido do subdesenvolvimento.

\section{INDUSTRIALIZAÇÃO SUBDESENVOLVIDA: DA ESTAGNAÇÃO À DEPENDÊNCIA}

A década que separa a publicação de Dialética do desenvolvimento (I964) e O mito do desenvolvimento econômico (I974) marcou significativa modificação no perfil da produção de Celso Furtado. Eventos como o golpe militar, que impôs o seu exílio, o esgotamento do ciclo de crescimento da industrialização por substituição de importações e a nova dinâmica econômica internacional, com crescente presença das multinacionais no país, exigiram do autor uma revisão de algumas de suas teses. Para captar os sentidos e tendências da trajetória da economia brasileira naquela quadra histórica, Celso Furtado daria nova amplitude a sua interpretação, aprimorando a mobilização da dimensão sociopolítica no intuito de compreender a dinâmica das economias subdesenvolvidas ${ }^{\mathrm{I} 3}$.

Então dominantes no debate público, os economistas de matriz nacional-desenvolvimentista encontraram o auge de sua participação no governo de Juscelino

I2 Em sua Obra autobiográfica, ao discutir a passagem “da dependência tecnológica à cultural”, Celso Furtado ( 20I4, p. 4I2- 4I3) é vacilante. Reconhece uma "nova dimensão [...] em conexão com o comportamento da demanda”, mas reforça que a noção da dependência (tecnológica, no caso) já estava na essência das teses cepalinas. Esse esforço de coerência interpretativa fica ainda mais evidente quando Furtado ( 20I4, p. 9I) rememora sua passagem pelos Estados Unidos, em I95I, e o contato com os professores Bert Hoselitz e Melville Herskovits, que teriam estimulado seu olhar para a compreensão do desenvolvimento "de um ângulo interdisciplinar", com preocupação com a dimensão da cultura. Para o tema da cultura em Celso Furtado, ver: Cunha; Britto, 20II, p. 20.

I3 Mallorquin (2005, p.I6; p. 2I6) defende que esse é o momento em que Furtado singulariza sua abordagem estruturalista; Bielschowsky (200ob, p. 37) compreende essa reorientação, para as contribuições sociológicas, como uma tendência de toda a Cepal nos anos I960, tendo José Medina Echavarría como um dos principais mentores. 
Kubitschek. Presentes na formulação das diretrizes do Plano de Metas, no Conselho de Desenvolvimento Econômico, na Sudene, entre outras instâncias governamentais, vestiam uma aura otimista de expectativas para a transformação da sociedade brasileira via planejamento e industrialização. A esperança advinha dos resultados do ciclo de política de substituição de importações, que, todavia, toparia com seus limites, ilustrados pela expansão da inflação, pelos gargalos da balança de pagamentos e pela queda do crescimento do início dos anos I960 (BIELSCHOWSKY, 2000a, p. 4I0-4I3).

Na segunda metade da década de I960, no instaurado cenário de crise, a política econômica nacional-desenvolvimentista seria combatida por diferentes matrizes ideológicas. Economistas ortodoxos questionavam as teses estruturalistas, atacando os efeitos das práticas protecionistas da política de substituição de importações, assim como advogando a favor das concepções monetaristas de combate à inflação. Para Love (I998, p. 43I-433; p. 439), a esquerda, por seu turno, lançava as primeiras teses em torno dos limites e dos exageros da política de substituição de importações, fosse por conta da natureza intensiva de capital, poupadora de mão de obra, fosse pelos estrangulamentos provocados pela introdução da diversificada estrutura industrial.

O golpe militar de I964 provocou repercussões no ambiente intelectual, decretando a crise do "ciclo ideológico do desenvolvimentismo" ${ }^{4}$. A partir de então, economistas e cientistas sociais opositores ao regime formulariam suas ideias de maneira mais acabada sobre a crise dos anos I960, integrando o projeto de "desenvolvimento, distribuição de renda e justiça social", herdado do desenvolvimentismo nacional, "em novos modelos de interpretação do desenvolvimento capitalista brasileiro (modelos de dependência e estagnacionismo)" (BIELSCHOWSKY, 2000a, p. 422) ${ }^{\mathrm{I}}$.

Tendo o projeto nacional-desenvolvimentista sido abortado, a interpretação de Celso Furtado vai expondo, de maneira cada vez mais aberta e crítica, que as trajetórias econômicas nacionais dependiam, antes de tudo, de escolhas e decisões políticas. O golpe de 1964 era a materialização dessa relação entre escolhas políticas e as ações econômicas. Em I968, com a publicação do livro Um projeto para o Brasil, afloram os primeiros traços de sua discordância ao novo sentido do projeto nacional empreendido pelo governo militar. A obra publicada meses antes do AI- 5 apresentava alguns traços que seriam refinados posteriormente em obras como Análise do "modelo" brasileiro (I972) e o $\mathrm{O}$ mito do desenvolvimento econômico (I974), constituindo um bloco de textos voltados para a reflexão sobre os limites do desenvolvimento dependente.

Antes, contudo, as reflexões de Celso Furtado estavam mais centradas no caráter da crise do modelo de substituição de importações e da nova conjuntura da economia internacional. Exilado após o golpe militar de 1964, e antes de seguir para os Estados Unidos, onde permaneceria um ano em Yale, Celso Furtado passou uma

I4 Reconhecemos que a ideia de "fim do desenvolvimentismo" pode ser problematizada, mas entendemos que o autor estabelece um recorte dentro de seu estudo, avaliando o ciclo do desenvolvimentismo no ambiente democrático. Para o estudo sobre o conceito do desenvolvimentismo, ver: Fonseca, 2015.

I5 João Manuel Cardoso de Mello (I975, p. I2-I3) ilustra a posição de como a industrialização não teria cumprido com a promessa de superação do subdesenvolvimento: "E assim chegamos aos meados da década dos I960, quando a morte do movimento social nacional-desenvolvimentista ficou evidente”. 
breve temporada em Santiago do Chile. Voltava à cidade sede da Cepal, ambiente de encontro com outros intelectuais latino-americanos, naquela que seria a atmosfera de formulação da teoria da dependência (LOVE, I998, p. 443; MALLORQUIN, 2005, p. 208).

No Chile, Furtado aproveitou a oportunidade para promover um ciclo de seminários no Instituto Latino-americano de Planificação Econômica e Social (Ilpes). Conforme registrado em suas memórias, ao oferecer um balanço das contribuições da Cepal e uma análise da conjuntura de crise das economias latino-americanas, teria submetido à discussão duas teses: uma sobre a forma de propagação do progresso técnico dos países centrais para a periferia; outra sobre o caráter da industrialização subdesenvolvida, que, ao se apropriar de tecnologia de elevada produtividade e de padrão de consumo dispendioso, provocava tendências que freavam a industrialização na periferia (FURTADO, 20I4, p. 4IO-4II).

Essas duas teses apareceriam de maneira sistematizada em I966, com a publicação de Subdesenvolvimento e estagnação na América Latina. A obra produziu significativo debate em torno da tese estagnacionista, recebendo relevantes críticas - tais como as de Maria da Conceição Tavares e José Serra ([I97I 2000) ${ }^{16}-$, que, de alguma forma, seriam absorvidas em suas obras posteriores (MALLORQUIN, 2005, p. 22I) ${ }^{\mathrm{I7}}$.

Quase como um divisor de águas na interpretação furtadiana, é possível observar em suas obras, entre os anos de 1966 e I968, tanto a incorporação de novos conceitos, como a construção de uma nova abordagem sobre os desafios do subdesenvolvimento latino-americano. Assim como ocorrera com a "revolução cepalina”, quando uma nova interpretação emergiu no debate público e intelectual dos anos I950, os anos finais da década de I960 observam o nascimento da teoria da dependência. Uma teoria que surgiu no ambiente de outros debates - absorvendo algumas de suas proposições -, como aquelas sobre o caráter da burguesia nacional, sobre a atuação das multinacionais na economia mundial e sobre a crise do processo de substituição de importações.

Em Subdesenvolvimento e estagnação, a problemática central para Celso Furtado era a de compreender a dimensão da crise dos anos I960, tendo como principal variável de análise o caráter da desigual propagação do progresso tecnológico. Assim, para o autor, as causas da crise ainda eram encontradas em variáveis mais econômicas do que sociológicas: a dinâmica da industrialização subdesenvolvida, ao alcançar a produção de bens duráveis e de capital, encontraria sensíveis tendências ao desequilíbrio. Absorvendo uma tecnologia poupadora de mão de obra e atendendo um mercado restrito com produtos diversificados, a substituição de importações

I6 Para Plínio de Arruda Sampaio Jr. (I999, p. 49- 53), "Além da estagnação", de Tavares e Serra ([I97I] 2000), marca uma ruptura no debate ao restringir a discussão sobre desenvolvimento aos aspectos da acumulação de capital e do crescimento econômico.

I7 Para Maurício Coutinho, todavia, a interpretação de Celso Furtado na década de I970, preservou sua leitura sobre a dinâmica da economia latino-americana: "os novos temas e desenvolvimentos trazidos pelos trabalhos do início dos anos setenta não deixam de ser compatíveis com variantes da abordagem histórico-estrutural apresentadas em textos de anos anteriores, especialmente Subdesenvolvimento e Estagnação" (COUTINHO, 2019, p. 754). 
produzia o "monopólio ou o oligopólio e uma progressiva concentração da renda" (FURTADO, I966, p. 39).

Celso Furtado, à luz das evidências econômicas daquele momento, inicia sua revisão das teses da Cepal no sentido de questionar a capacidade da industrialização e da diferenciação do sistema produtivo em produzir as condições para a superação do subdesenvolvimento. Acreditando na capacidade do Estado de reverter a estagnação latino-americana, essa de "caráter estrutural", oferece na parte final da obra instrumentos de planejamento para o enfretamento da crise (FURTADO, I966, p. 89).

A leitura de A hegemonia dos Estados Unidos e o subdesenvolvimento da América Latina, publicado em I973 no Brasil, é um relevante exercício para avaliar o percurso interpretativo do autor. A obra era resultado de algumas revisões dos ensaios produzidos para Subdesenvolvimento e estagnação na América Latina (I966) e para Um projeto para o Brasil (I968) ${ }^{\mathrm{I}}$. Mesmo que o autor indique que as alterações fossem meramente "formais", vale ressaltar como Furtado incorpora em sua nova versão o conceito de "dependência externa", termo que seria central para o autor avaliar o subdesenvolvimento tanto em sua dimensão de difusão do progresso tecnológico, como em sua dimensão sociológica e cultural ${ }^{\mathrm{I}}$.

$\mathrm{Na}$ "nota introdutória" da obra, o autor remete essa "explicação teórica global" sobre os fenômenos do subdesenvolvimento e da dependência aos textos "Dependencia externa y teoría económica" (I97I) e Teoria e política do desenvolvimento econômico (I967) (FURTADO, I973, p. 2). Se para o artigo de I97I a ideia de "dependência" já estava significativamente lapidada, em Teoria e política, obra que retoma suas teses presentes em Desenvolvimento e subdesenvolvimento, o economista apresenta o quadro mais geral sobre a teoria do subdesenvolvimento, recolocando sua teoria histórico-estruturalista. Todavia, uma inovação relevante no capítulo "Dependência externa e subdesenvolvimento" de Teoria e política é a ideia de "enclaves sociais", isto é, da existência nas economias subdesenvolvidas de grupos culturalmente dependentes de subsistemas dominantes, alegando que o "dualismo" teria início numa dimensão cultural, que se traduzia em termos econômicos, pela descontinuidade da estrutura produtiva (FURTADO, I967 [I977], p. 249).

Ademais, a chave explicativa para apreender a nova perspectiva do autor sobre a dependência deve ser encontrada na primeira nota de rodapé de $\mathrm{A}$ hegemonia dos

I8 A obra foi publicada em inglês e francês em I969, recebendo nova revisão para a edição em português. Furtado (I973, p. I-2) reconhece que as críticas recebidas pelo texto o ajudaram a abordar o tema com mais clareza.

I9 Reproduzindo as ideias de Um projeto para o Brasil, Furtado reafirma em A hegemonia dos Estados Unidos:

"As duas dimensões de desenvolvimento - a econômica e a cultural - não podem ser captadas senão em conjunto” (FURTADO, I973, p. I29). Mallorquin (2005, p. 238) conclui, ao comparar Subdesenvolvimento e estagnação com Um projeto para o Brasil e Análise do "modelo" brasileiro, que: "os conceitos da relação produto/ capital e coeficiente de capital perdem proeminência, convertendo-se em algo secundário para explicar o funcionamento específico do capitalismo brasileiro, levando à dianteira, desta vez, os aspectos políticos institucionais”. Tais ideias de ampliação do escopo da análise são reafirmadas em outros trabalhos: Bianconi, 20I6; Bugelli; Pires, 20II. 
Estados Unidos, quando Furtado indica o livro Análise do "modelo" brasileiro para uma leitura mais "compreensiva do problema da dependência" (FURTADO, I973, p. 8) ${ }^{20}$.

Ao cotejar o primeiro capítulo de Subdesenvolvimento e estagnação com o de $A$ hegemonia dos Estados Unidos, encontramos o mesmo ensaio introdutório sobre o quadro econômico internacional, com revisões mais do que "formais", como teria sugerido o autor. Apesar dos títulos dos capítulos terem sido bastante alterados "Em busca de uma ideologia do desenvolvimento" (I966) e "O subdesenvolvimento no quadro do capitalismo industrial" (I973) -, os ensaios analisam a construção do cenário do capitalismo contemporâneo, explicando a essência do fenômeno do subdesenvolvimento. Algumas mudanças percebidas são sugestivas.

No primeiro capítulo da obra da década de I970, Furtado substitui em alguns momentos a denominação dos países latino-americanos como países subdesenvolvidos, supostamente por falar agora para um público ainda mais amplo. Ademais, o capítulo da década de I960 possui quatro páginas finais voltadas para uma discussão sobre os "caminhos à ação política na América Latina”. Essas páginas, suprimidas em I973, são substituídas por um curto fechamento: "A inadequação desses esquemas ideológicos é particularmente grave, em razão da preeminência dos problemas a que aludimos. Um trabalho criador neste plano é essencial e urgente" (FURTADO, I973, p. I8).

Mas a alteração de fundo que merece ser observada aparece na nova redação dos parágrafos iniciais. Depois do primeiro parágrafo da obra ter sido ligeiramente reescrito, Furtado insere no segundo parágrafo uma ideia-chave para o novo ensaio, completamente ausente no livro de I966. Partindo da mesma explicação sobre a origem do subdesenvolvimento como criação do próprio desenvolvimento - isto é, da divisão do trabalho erigida a partir da revolução industrial -, o ensaio complementa: "As relações que se estabelecem entre esses dois tipos de sociedades envolvem formas de dependência que tendem a autoperpetuar-se” (FURTADO, I973, p. 8).

O termo dependência, inexistente em sua obra sobre a estagnação, torna-se central na compreensão da permanente "armadilha" do subdesenvolvimento. Vale reforçar que, em Um projeto para o Brasil, Furtado (I968, p. 20-23) já dedica uma seção para descrever "as características do desenvolvimento dependente", as quais indicavam o caráter reflexo da economia periférica ao "progresso tecnológico presente nos polos dinâmicos da economia mundial”. Em I973, mesmo mantendo o sentido de subordinação das economias periféricas sobre o controle do progresso tecnológico, isto é, a tradicional noção de dependência alicerçada numa determinada divisão social do trabalho, o economista enfatiza a ideia de uma dependência que "teve como ponto de apoio principal o controle, por grupos integrados nas economias dominantes, daquelas atividades produtivas, instaladas nas economias dependentes" (FURTADO, I973, p. 8).

$20 \mathrm{Na}$ apresentação do "quadro estrutural mais amplo", de Análise do "modelo" brasileiro, Celso Furtado (I972, p. 3I) indica que o fluxo de novos produtos e de inovações tecnológicas, emitidas a partir dos países centrais, são os principais instrumentos de preservação das relações de dominação e dependência, isto é, "um efeito de dependência que decorre da forma como atualmente o progresso tecnológico se propaga do centro para a periferia do mundo capitalista”. 
A dependência externa, relacionada ao padrão financeiro e tecnológico, era um diálogo direto com as teses cepalinas sobre a propagação do progresso tecnológico ou, como quer Joseph Love (I998, p. 46I), vinculando-se às teses do estruturalismo latino-americano sobre a perspectiva do centro-periferia e das trocas desiguais. $\mathrm{O}$ papel desempenhado pelas multinacionais nas economias periféricas abria um novo campo de estudos. Em Subdesenvolvimento e estagnação a presença das multinacionais é notada e problematizada, quando o autor se pergunta qual seria o tipo de organização política compatível com o novo sistema econômico regional controlado por "poderosas sociedades anônimas norte-americanas" (FURTADO, I966, p. 43).

Furtado se vale de autores como Andrew Hacker e Adolph Berle para discutir o novo caráter das grandes corporações na economia internacional, temática que seria mais bem desenvolvida em seus dois últimos ensaios reunidos em Um projeto para o Brasil. Nessa obra Celso Furtado apontava para a "reestruturação da economia internacional" e para o "fenômeno da conglomeração", isto é, para a nova dinâmica política e econômica mundial, consequência da massiva presença das multinacionais na América Latina. Antes de se instalar em Paris, Furtado passou um ano no Centro de Estudos sobre o Crescimento Econômico da Universidade de Yale. Tendo como colega de trabalho o economista Stephen Hymer (I976), autor de The international operations of national firms: a study of direct foreign investment, Celso Furtado acabou por assimilar nova temática que emergia sobre os estudos da economia internacional. Hymer foi um dos pioneiros autores, como reconhece Furtado (20I4, p. 469-470), a destacar a importância do papel das empresas transnacionais na dinâmica econômica do período ${ }^{21}$.

Esse processo de instalação das empresas multinacionais nas economias subdesenvolvidas passaria a cumprir papel relevante na interpretação de Celso Furtado a partir de então. Para o economista, a presença das multinacionais reduzia ainda mais os sistemas de decisão nacionais, processo acentuado nos últimos anos no país. Se a instalação dos conglomerados já era realidade no Brasil desde o Plano de Metas, com o golpe militar a estratégia de industrialização via investimento estrangeiro se aprofundaria. Para o autor, a conjuntura de crise econômica latino-americana dos anos I960 teria aberto maiores oportunidades para a entrada dos investimentos estrangeiros.-

Assim, mesmo com a industrialização de países da América Latina, como Argentina e Brasil, Celso Furtado (I968, p. II4) argumentava que a pauta de exportação desses países, ainda dependentes das velhas estruturas exportadoras de matérias-primas, demonstrava a dimensão da nova forma de dependência do exterior. A crescente presença das empresas multinacionais nas economias estagnadas agravava a crise estrutural da capacidade de importar, por conta das remessas de lucros e dividendos,

2I Sobre Hymer, Furtado lembra em sua biografia: "Os seus trabalhos foram seminais para a compreensão da transnacionalização como forma emergente de organização das atividades econômicas. Foi para mim de grande importância tomar contato com os trabalhos de Hymer e ter podido discutir amplamente com ele sobre o fenômeno da transnacionalização das empresas. Graças a isso, foi-me possível captar nos anos seguintes a verdadeira natureza do sistema bancário internacional, o qual viria a ser o elemento determinante na evolução da economia capitalista a partir dos anos I970" (FURTADO, 20I4, p. 469-470). 
reduzia a capacidade de integração do setor industrial com atividades exportadoras e produzia debilidade do processo de formação dos centros nacionais de decisão.

A reflexão de Furtado indicava que o estreitamento da capacidade de ação dos Estados nacionais, assim como do papel das classes empresariais nacionais, decorria do caráter dependente das estruturas periféricas, reiterado pela expansão das empresas transnacionais. A classe de empresários brasileiros, assumindo tarefas auxiliares aos setores industriais absorvidos pelas multinacionais, renunciava ao sentido de um desenvolvimento nacional.

Essa nova dimensão de sua análise sobre a presença das multinacionais interferindo nos centros de decisão nacionais inseria o autor no debate sobre o caráter da burguesia nacional. Nas palavras do autor: "A redução a um papel de dependência da classe de empresários nacionais, interrompeu na América Latina o processo de desenvolvimento autônomo de tipo de capitalista, o qual chegara apenas a esboçar-se" (FURTADO, I968, p. I32-I33). Para Furtado, o enfraquecimento do Estado como centro autônomo de decisões não abria espaço para a iniciativa privada, mas limitava a formação de um sistema econômico nacional, isto é, um uma economia que atendesse os interesses da coletividade nacional.

No livro de I968, Celso Furtado parece incorporar a ideia dos limites do papel do empresariado brasileiro na condução de um projeto nacional de desenvolvimento. Ainda que Furtado não se valha do conceito de revolução brasileira, há relevantes semelhanças entre suas ideias e aquelas que podem ser encontradas nos trabalhos sobre o empresariado nacional de Fernando Henrique Cardoso (I964) e Luiz Carlos Bresser-Pereira (I963; I964) ${ }^{22}$. Para esses autores, a burguesia brasileira não teria cumprido seu papel histórico de produzir um projeto nacional, mas, ao assumir as franjas de uma industrialização liderada pelas empresas multinacionais, conduziu o país a nova dependência.

Derivada da análise da fragilidade da burguesia nacional, é possível encontrar outra identidade entre a produção de Celso Furtado e a produção de Cardoso, nesse caso Dependência e desenvolvimento na América Latina (I970), obra publicada com Enzo Faletto. Conforme os autores, era preciso produzir uma análise integrada do processo histórico, isto é, uma análise econômica do desenvolvimento, associada à análise sociológica, partindo dos condicionantes econômicos mundiais, passando pela estrutura do sistema produtivo nacional e seu vínculo com o mercado externo, e a configuração histórica estrutural de tais sociedades - das relações de poder e movimentos políticos sociais (CARDOSO; FALETTO, I970, p. 23-24).

A temática da perda de autonomia do Estado nacional naquela conjuntura, como resultado da expansão das empresas multinacionais no Brasil, exigia

22 Caio Prado Jr. discute também o caráter da burguesia nacional, mais tarde, em A revolução brasileira (I966). Francisco de Oliveira (2003, p. 26) defende que Fernando Henrique Cardoso teria acertado em sua sugestão de uma articulação entre a burguesia nacional e o capital estrangeiro, indicando "a ausência de um projeto nacional”, valendo-se do método marxista e da identificação dos atores concretos das transformações. 
uma análise da industrialização também por meio de determinantes internos ${ }^{23}$. Reconhece Furtado (20I4, p. 4I6) que "Fernando Henrique Cardoso chegou a conclusão similar [à de Furtado] ${ }^{24}$ pela mesma época quando introduziu o conceito internacionalização do mercado interno".

Em meio aos seminários de Santiago do Chile, em julho de I964, os autores teriam tido oportunidade de discutir a nova realidade latino-americana, na qual se reconhecia a perda de autonomia de decisão, em que a industrialização produz uma forma mais complexa de dependência (FURTADO, 20I4, p. 4I6-4I7). Evidentemente que essa identidade de análise sobre o processo de industrialização dependente não aproxima Furtado no sentido profundo da interpretação de Cardoso e Faletto, isto é, na possibilidade de compatibilizar o processo de desenvolvimento com uma situação de dependência.

No momento em que Celso Furtado, ao que parece, se armava intelectualmente para enfrentar o debate teórico sobre a dependência, que aflorava no debate latino-americano, o economista procura manter sua independência intelectual para seguir um percurso particular de análise. A nova formulação é coroada com as obras Análise do "modelo" brasileiro e $O$ mito do desenvolvimento econômico e o conceito de modernização nelas mobilizado. As economias periféricas, com industrializações dependentes, não alçavam o "verdadeiro desenvolvimento" - com homogeneização dos benefícios do progresso técnico-, mas sim uma espécie de modernização, "a assimilação do progresso tecnológico nos padrões de consumo" (FURTADO, I972, p. II) 25.

Em suma, se a dimensão da desigual difusão do progresso técnico continuava como base de sua análise, agora, contudo, a dimensão das modificações do padrão de consumo teria papel decisivo para esclarecer os limites do crescimento econômico periférico. Para os países subdesenvolvidos o processo de difusão da revolução industrial ocorria, acima de tudo, por meio da transformação dos padrões de consumo para uma minoria da população. Sendo a renda per capita incompatível com o nível de acumulação desejada pelas classes abastadas, a concentração da renda tornava-se peça central na engrenagem do subdesenvolvimento.

O "modelo" brasileiro, materializado pelas elevadas taxas de crescimento do milagre, para Furtado, era a materialização desse processo: uma rápida

23 A introdução da tese de João Manuel Cardoso de Mello ilustra essa proposição. Para o autor a economia política da Cepal teria como tema a "problemática industrialização nacional, a partir de uma situação periférica”, de forma que a análise sobre a industrialização prescindia de qualquer esquema endógeno de acumulação, existindo apenas impactos internos decorrentes da importação de certa tecnologia (MELLO I975, p. 9-II).

24 Ao comentar a similaridade entre as visões, a proposição de Furtado (20I4, p. 4I6) em suas memórias era a de que "os homens mais capazes surgidos nas indústrias locais puderam ser cooptados para integrar a nova classe gerencial a serviço dos conglomerados. A ação empresarial nacional ficou restringida a setores secundários ou decadentes, ou ao trabalho pioneiro, isto é, à abertura de novas frentes a ser mais adiante ocupadas pelas grandes organizações estrangeiras".

25 Na síntese de I974, modernização é o "processo de adoção de padrões de consumo sofisticados (privados e públicos) sem correspondente processo de acumulação de capital e progresso nos métodos produtivos" (FURTADO, I974, p. 8I). 
industrialização, alicerçada pela instalação das empresas transnacionais com elevada estrutura tecnológica, poupadora de mão de obra, que garantia para uma concentrada parcela da população o acesso aos bens de consumo mais "modernos" do capitalismo. Em suma, quanto mais rápida e diversificada fosse a assimilação do consumo - para países com limitados recursos financeiros e estruturas sociais tão desiguais -, mais lenta seria a difusão do progresso tecnológico.

Na primeira metade da década de I970, portanto, depois de uma fase de acelerado crescimento econômico no Brasil, Celso Furtado parece se afastar da polêmica sobre a estagnação, mas agora faz sua crítica às teses que associam dependência e desenvolvimento. Ainda que suas obras do período fossem uma crítica direta à política econômica do governo militar, Celso Furtado, mesmo sem explicitar, está produzindo uma significativa crítica às posições defendidas por autores como Cardoso e Faletto, ou mesmo Tavares e Serra, a respeito da noção do "desenvolvimento" capitalista brasileiro.

Nesse sentido, é preciso considerar que existe uma diferença sensível na qualificação do termo "desenvolvimento" entre os autores. Enquanto Cardoso e Faletto, como também os representantes do capitalismo tardio, por exemplo, Maria da Conceição Tavares e João Manuel Cardoso de Mello, apreendem a noção de desenvolvimento dentro da tradição marxista do desenvolvimento das forças produtivas, o conceito para Furtado assume uma proposição "valorativa", sendo que fazem parte do processo de desenvolvimento as transformações voltadas à garantia da distribuição de renda e da homogeneização social. Por isso, para Cardoso e Faletto o desenvolvimento não é incompatível com a condição de dependência, visto que o desenvolvimento do capitalismo é em si concentrador de renda, excludente e gerador de crises. Para Furtado, por outro lado, a problematização do conceito de desenvolvimento e sua polarização com o termo de modernização definem a incompatibilidade entre desenvolvimento e dependência (ALMEIDA, 2009) ${ }^{26}$.

Se, por um lado, Furtado (I972, p. 28) assimilava as críticas sobre a estagnação, admitindo que não existia "evidência de correlação negativa entre o grau de concentração da renda e o nível de produtividade industrial", por outro lado, substituía o conceito de "desenvolvimento" pelo de "modernização" para caracterizar o novo ciclo de crescimento econômico brasileiro, concentrador de renda e autoritário. Os limites para a superação do atraso já não eram apenas econômicos, mas a dimensão da dependência era cultural, um "tipo semelhante de colonização cultural" dos grupos que se apropriavam do excedente da economia (FURTADO, I974, p. 82-84).

O questionamento da perspectiva do desenvolvimento associado, não obstante, mesmo que numa leitura bastante crítica do cenário político nacional, não aproximaria Celso Furtado da interpretação ou do projeto social dos autores dependentistas de vertente marxista. Mesmo que o enquadramento mais geral das relações desiguais entre países centrais e periféricos na economia capitalista se assemelhassem

26 É ilustrativo, nesse sentido, o prefácio da edição americana de Dependência e desenvolvimento na América Latina, em que os autores explicitam as contradições intrínsecas do desenvolvimento capitalismo, indicando que a superação dessas contradições somente poderia ser alcançada por meio do socialismo (CARDOSO; FALETTO, 2008). 
entre Furtado e André Gunder Frank, a posição marxista era de uma inevitável imposição externa sobre as estruturas internas, negando qualquer condição de um desenvolvimento autônomo na periferia, cabendo a revolução socialista como solução (PALMA, I978, p. 900; LOVE, I998, cap. I2; BRESSER-PEREIRA, 20I0, p. 32) ${ }^{27}$.

Mesmo que Celso Furtado reconhecesse o caráter da burguesia nacional como dependente - alienada e cosmopolita -, mantinha a expectativa de reconstruir um projeto de desenvolvimento nacional, por conta do caráter relativo e contraditório dessa dependência (BRESSER-PEREIRA, 20Io, p. 38) -, o que poderia permitir a reversão do quadro de dependência, não mais somente pelo progresso técnico, mas agora por meio da cultura. Assim, Celso Furtado abriria uma terceira perspectiva interpretativa da teoria de dependência, a nacional-dependente, como diz Bresser-Pereira (20I0, p. 34), na qual Furtado entende que a luta contra a dependência deveria passar pela retomada do controle nacional dos recursos não renováveis do país e do mercado interno, assim como a criação de meios para superar a dependência financeira e a dinâmica de incorporação do progresso tecnológico (LOVE, I998, p. 442).

Nos anos I970, a concepção de desenvolvimento de Celso Furtado não estava limitada mais ao campo dos economistas, a nova dimensão da dependência o levou a explorar outras fronteiras do conhecimento ${ }^{28}$.

\section{CRIATIVIDAdE E DEPENDÊNCIA: AS CONEXõES FUNDAMENTAIS ${ }^{29}$}

Na segunda metade de década de I970 a reflexão furtadiana assume nova orientação, no que será considerada a face "filosófica" de sua trajetória intelectual. Como destaca Francisco de Oliveira (2003, p. 32), a nova direção permitia a Furtado escapar dos estreitos limites técnicos e teóricos da ciência econômica, como também possibilitava ao economista conciliar o ecletismo e a criatividade - marcas de seu estilo de pensar, com a reflexão histórica de maior alcance.

Orientação bem expressa em Criatividade e dependência na civilização industrial, de I978, obra em que Furtado passa pela história de longa duração para explorar os momentos de emergência e difusão da civilização industrial pelo mundo. Trata-se de

27 Vale lembrar que a posição de Rui Mauro Marini sobre a superexploração e o subimperialismo avançava na interpretação de Frank ao identificar a luta de classes internas aos países dependentes, mas reiterava a revolução como única saída para superar a dependência.

28 Sampaio Jr. (I999, p. I74) defende que a teoria da dependência para Furtado estuda os nexos externos da subordinação econômica e política da periferia, estruturando a dependência em três condicionantes do processo de acumulação: dependência cultural, dependência tecnológica e financeira e dependência dos fluxos de renda.

29 O subtítulo faz referência ao segundo capítulo de $O$ mito do desenvolvimento econômico, de mesmo título, ensaio em que Furtado procurou evidenciar uma "teoria da dependência que se afasta das simples afirmações doutrinárias pois pode ser submetida a teste”, partindo da constatação de que os países dependentes, exportadores de produtos primários "absorvem tecnologia mais rapidamente no nível dos produtos finais do que dos processos produtivos" (D’AGUIAR, 20I3, p. I2), como Furtado afirmaria posteriormente em carta enviada a Joseph Love já no início da década de I980. 
um "antilivro acadêmico", nos termos do autor, escrito com a intenção declarada de recompor a visão global que já não caberia nos "tubos de ensaio das ciências sociais" (FURTADO, [I978] 2008, p. 34) ${ }^{30}$.

No livro em questão, Celso Furtado retoma suas análises anteriores e as coloca em um quadro mais amplo: as estruturas híbridas e de caráter dualista que constituíam o fenômeno do subdesenvolvimento são agora pensadas em um contexto histórico ampliado. Assim, por exemplo, há grande diferença entre as industrializações tardias, como as ocorridas na Rússia, no Japão e na América Latina.

Nos casos russo e japonês, o processo de assimilação da civilização industrial teria ocorrido como resultado da "tomada de consciência do atraso na acumulação e da ameaça de dominação externa” (FURTADO, [I978] 2008, p. 69). Na Rússia, a assimilação iniciada pelo regime czarista no século XIX teria sido acelerada a partir da revolução bolchevique, feita sob rígido sistema de controle social, o que levou o Estado a um papel central na vida econômica e social do país, produzindo o que Furtado considera um verdadeiro esgarçamento do "tênue tecido da sociedade civil" (FURTADO, [I978] 2008, p. 68).

No Japão, o transplante da civilização industrial foi encarado como condição de sobrevivência do país como nação soberana, o que foi feito a partir de uma aliança entre o Estado e a aristocracia tradicional, afirma Furtado ([I978] 2008, p. 67), criando um tipo específico de empresa capitalista que atuava como "uma projeção dos grupos sociais tradicionais". Nesses dois casos, a civilização industrial foi absorvida a partir de objetivos nacionais bem delimitados.

O caso da América Latina é diferente. A via latino-americana de acesso à civilização industrial pode mesmo ser considerada como um subproduto da dominação externa, segundo Furtado. Trata-se de uma via de acesso condizente com o quadro então vigente da divisão internacional do trabalho - de um centro industrializado e uma periferia exportadora de produtos primários, que acabaria por conduzir toda a região a uma "situação de dependência estrutural" (FURTADO, [I978] 2008, p. 69).

Essa via indireta de acesso da América Latina condicionou o sentido da integração da região nos mercados internacionais, assim como as subsequentes modernizações nos padrões de consumo locais e mesmo as mudanças na paisagem urbana. Processo cujas fontes de financiamento locais eram insuficientes, por contar com não mais do que "um excedente extraído de exportações originárias de uma agricultura extensiva ou da alienação de recursos não renováveis" (FURTADO, [I978] 2008, p. 93).

A partir daí se compreende, por exemplo, o sentido do processo de industrialização por substituição de importações na região, que Furtado vê como um subsistema descolado do nível de produtividade local, com alta densidade de capital e pequena capacidade de geração local de empregos. Isto é, um subsistema estruturalmente vinculado a economias mais avançadas que acaba por renovar e aprofundar as relações de dependência (FURTADO, [I978] 2008, p. 75).

Entendem-se também os obstáculos ideológicos que esse tipo de dependência

30 No prefácio à edição mais recente da obra, Alfredo Bosi (2008, p. I3) destaca a originalidade da interpretação furtadiana, assim como sua "vigorosa síntese histórica e conceitual da civilização industrial”. 
estabelece, uma vez que valores como o racionalismo e o liberalismo, que surgiram visando à superação do Antigo Regime, quando transpostos para as situações de dependência adquirem outro significado e transformam-se em instrumento de reforço mental e ideológico da dependência (FURTADO, [I978] 2008, p. 7I).

Em certo sentido, já durante o processo de redemocratização, a perspectiva de Furtado sobre a dependência seria a base para sua crítica aos rumos da integração econômica que o Brasil passaria a vivenciar entre os anos I980 e I990. Isto é, enquanto a visão da teoria da dependência associada mostrava-se vitoriosa politicamente, ilustrada com a eleição de um de seus principais teóricos para presidência da república, a perspectiva marxista da dependência sobreviveria fundamentalmente nos meios acadêmicos, perdendo espaço no campo político com a crise do socialismo.

A leitura nacional dependente de Celso Furtado, ao longo dos anos I980, reforçava a centralidade da democracia como instrumento político para a construção de um projeto nacional, sustentado por uma coalizão de classes. No quadro econômico, reiterava a necessidade de retomada dos centros internos de decisão como instrumento central para viabilizar uma política mais autônoma efetivamente voltada aos interesses nacionais. Em A nova dependência, por exemplo, no quadro do endividamento externo latino-americano, Furtado (I982, p. 46; p. 59) sustentava a ideia de que os países devedores deveriam criar uma organização para negociar em bloco com as instituições credores.

A reflexão cultural seria novamente mobilizada por Furtado nos anos I980. Cultura e desenvolvimento em época de crise (I984), redigido dois anos antes de assumir o posto de ministro de Cultura, tem o objetivo mais imediato de procurar saídas para uma crise econômica que anunciava o que viria a ser uma década perdida. Como membro da Comissão Mundial de Cultura e Desenvolvimento, estabelecida no ano de 1992 pela Organização das Nações Unidas para a Educação, a Ciência e a Cultura (Unesco), Furtado ([I995] 20I2, p. II6) parece concluir que a própria sobrevivência da civilização dependia da solidariedade entre povos e culturas e de mecanismos de cooperação internacional plurais e participativos.

Mesmo no final da década de I990, sua questão para o Brasil seria ainda a de ter ou não acesso à criatividade (FURTADO, I999, p. 67). Afinal, como concluíra antes, a luta contra a dependência seria parte de um processo mais amplo de desenvolvimento, que de fato somente poderia ocorrer "com a liberação da capacidade criadora de um povo” (FURTADO, [I978] 2008, p. I62), também expressa em sua capacidade de pensar seus próprios desígnios.

Assim, a totalidade da reflexão cultural de Furtado parece recompor todo o sentido da obra do economista ao explicar as situações de dependência. A superação da dependência passava pela construção de um projeto nacional autônomo, em que os objetivos econômicos e sociais atendessem aos interesses do país. Nessa orientação, é possível distinguir as faces do servidor público do Departamento Administrativo do Serviço Público (Dasp), do economista da Cepal, do diretor do Banco Nacional de Desenvolvimento Econômico (BNDE), do superintendente da Sudene, do ministro do Planejamento, do teórico do subdesenvolvimento, do ministro da Cultura, entre tantas outras.

Ao apresentar o todo quando visto da periferia, ao seguir o rastro de vidas e fés 
destruídas pela difusão da civilização industrial, na citação de Eliot ${ }^{3 \mathrm{I}}$, o intérprete do Brasil, da América Latina e da dependência agora se torna intérprete do mundo, que se descortina como fantasia organizada. Ao final do percurso, Furtado parece terminar por onde começou, isto é, pela tarefa de interpretar a realidade e despertar as consciências para a luta contra o subdesenvolvimento.

\section{SOBRE OS AUTORES}

RÔMULO MANZATTO é economista (FEA/USP) e mestre em Ciência Política pelo Departamento de Ciência Política da Faculdade de Filosofia, Letras e Ciências Humanas da Universidade de São Paulo (DCP/FFLCH/USP).

romulo.manzatto@gmail.com

https://orcid.org/0000-0003-0814-7392

ALEXANDRE MACCHIONE SAES é professor do Departamento de Economia da Faculdade de Economia, Administração e Contabilidade da Universidade de São Paulo (FEA/USP) e bolsista Produtividade CNPq-2. alexandre.saes@usp.br

https://orcid.org/0000-0003-4274-I993

\section{REFERÊNCIAS}

ALMEIDA, J. E. D. Subdesenvolvimento e dependência: uma análise comparada de Celso Furtado e Fernando Henrique Cardoso. Tese (Doutorado em Economia). 205 p. Programa de Pós-Graduação em Economia, Universidade Federal do Rio Grande do Sul, 2009.

BIANCONI, R. Estagnação latino-americana e estratégia brasileira de desenvolvimento: análises do início do exílio de Celso Furtado. História Econômica e História de Empresas, v.I9, n. I, 20I6, p. I55-I88. BIDERMAN, C.; COZAC, L. F. L.; REGO, J. M. Conversas com economistas brasileiros. São Paulo: Ed. 34, I996. BIELSCHOWSKY, R. Pensamento econômico brasileiro: ciclo ideológico do desenvolvimentismo. Rio de Janeiro: Contraponto, 2000a. BIELSCHOWSKY, R. Cinquenta anos de pensamento da Cepal. V. I. Rio de Janeiro: Record, $2000 \mathrm{~b}$. BOSI, A. Prefácio. In: FURTADO, C. Criatividade e dependência na civilização industrial. São Paulo: Companhia das Letras, 2008, p. 9-3I

3I Estamos nos referindo à epígrafe de Criatividade e dependência, em que Furtado ([I978] 2008) cita trecho de The rock, de T. S. Eliot: "The broken standards, the broken lives/ The broken faith on one place or another". 
BRESSER-PEREIRA, L. C. O empresário industrial e a revolução Brasileira. Revista de Administração de Empresas, São Paulo, v. 2, n. 8, jul., I963, p. II-27.

BRESSER-PEREIRA, L. C. Origens étnicas e sociais do empresário paulista. Revista de Administração de Empresas, São Paulo, v. 3, n. II, I964, p. 83-I03.

BRESSER-PEREIRA, L. C. As três interpretações da dependência. Perspectiva, São Paulo, v. 38, jul.-dez. 20IO, p. I7-48.

BRITO, L. O. B. de. Marxismo como crítica da ideologia: um estudo sobre os pensamentos de Fernando Henrique Cardoso e Roberto Schwarz. Tese (Doutorado em Ciência Política). Programa de Pós-Graduação em Ciência Política, Faculdade de Filosofia, Letras e Ciências Humanas, Universidade de São Paulo, 20I9.

BUGELLI, A. H.; PIRES, J. M. Uma revisão da teoria da estagnação de Celso Furtado e a crise econômica dos anos I960. Cadernos do Desenvolvimento, v. 6, n. 9, 20II, p. I9-4I.

CARDOSO, F. H. Empresário industrial e desenvolvimento econômico. São Paulo: Difel, I964.

CARDOSO, F. H.; FALETTO, E. Dependência e desenvolvimento na América Latina. Rio de Janeiro: LTC Editora, I970.

CARDOSO, F. H.; FALETTO, E. Repensando dependência e desenvolvimento na América Latina. In: SORJ, B.; CARDOSO, F. H. ; FONT, M. (org.). Economia e movimentos sociais na América. Rio de Janeiro: Centro Edelstein de Pesquisa Social, 2008. p. 4-20.

COUTINHO, M. Furtado e seus críticos: da estagnação à retomada do crescimento econômico. Economia e Sociedade, v. 28, n. 3, 20I9, p. 74I-759.

CUNHA, A. M.; BRITTO, G. When development meets culture: the contribution of Celso Furtado in the I970s. Textos para Discussão Cedeplar-UFMG 429, Universidade Federal de Minas Gerais, $20 I I$.

D’AGUIAR, R. F. Apresentação. In: D’AGUIAR, Rosa Freire (org). Essencial Celso Furtado. Organização, apresentação e notas de Rosa Freire d'Aguiar. São Paulo: Penguim Classics Companhia das Letras, 20I3, p. 7-I8.

FONSECA, P. C. D. Desenvolvimentismo: a construção do conceito. Texto para discussão - Ipea, 2IO3, Brasília, julho, 2015.

FURTADO, C. Formação de capital e desenvolvimento econômico. Revista Brasileira de Economia, Rio de Janeiro, v. 6, n. 3, set. I952, p. 7-45.

FURTADO, C. A economia brasileira: contribuição à análise do seu desenvolvimento. Rio de Janeiro: Ed. A Noite, I954.

FURTADO, C. Uma economia dependente. Rio de Janeiro: Ministério da Educação e Cultura, I956.

FURTADO, C. Perspectivas da economia brasileira. Rio de Janeiro: Iseb, I958.

FURTADO, C. Desenvolvimento e subdesenvolvimento. Rio de Janero: Fundo de Cultura, I96I.

FURTADO, C. A pré-revolução brasileira. Rio de Janeiro: Fundo de Cultura, I962.

FURTADO, C. Dialética do desenvolvimento. Rio de Janeiro: Fundo de Cultura, I964.

FURTADO, C. Subdesenvolvimento e estagnação na América Latina. Rio de Janeiro: Civilização Brasileira, I966.

FURTADO, C. Teoria e política do desenvolvimento econômico. São Paulo: Editora Nacional, I967.

FURTADO, C. Um projeto para o Brasil. 5. ed. Rio de Janeiro: Saga, I968.

FURTADO, C. Dependencia externa y teoría económica. El Trimestre Ecomómico, v.38, n. I50 (2), abril-junio I97I, p. 335-349.

FURTADO, C. Análise do "modelo" brasileiro. Rio de Janeiro: Civilização Brasileira, I972.

FURTADO, C. A hegemonia dos Estados Unidos e o subdesenvolvimento da América Latina. Rio de Janeiro: Civilização Brasileira, I973.

FURTADO, C. O mito do desenvolvimento econômico. 2. ed. Rio de Janeiro: Paz e Terra, I974. 
FURTADO, C. A nova dependência, dívida externa e monetarismo. Rio de Janeiro, Paz e Terra, I982.

FURTADO, C. A Revolução de I930 em perspectiva: Estado, estrutura e poder e processo político. (Debatedor). In: A REVOLUÇÃO de 30: seminário internacional realizado pelo Centro de Pesquisa e Documentação de História Contemporânea do Brasil (CPDOC) da Fundação Vargas. Rio de Janeiro, setembro de I980. Brasília: Editora da Universidade de Brasília, I982. (Coleção Temas Brasileiros 54).

FURTADO, C. Cultura e desenvolvimento em época de crise. I. ed. Rio de Janeiro: Paz e Terra, I984.

FURTADO, C. O longo amanhecer: reflexões sobre a formação do Brasil. I. ed. São Paulo: Paz e Terra, I999.

FURTADO, C. (I959). Formação econômica do Brasil. São Paulo: Companhia das Letras, 2007.

FURTADO, C. (1978). Criatividade e dependência na civilização industrial. São Paulo: Companhia das Letras, 2008.

FURTADO, C. (I959). A Operação Nordeste. In: FURTADO, C. O Nordeste e a saga da Sudene: I958-I964. Rio de Janeiro: Contraponto/Centro Internacional Celso Furtado de Política para o Desenvolvimento, 2009, p. 29-7I. (Arquivos Celso Furtado 3).

FURTADO, C. (1995). Cultura e desenvolvimento. In: FURTADO, C. Ensaios sobre cultura e o Ministério da Cultura. I. ed. Organização de Rosa Freire d’Aguiar. Rio de Janeiro: Contraponto/Centro Internacional Celso Furtado de Política para o Desenvolvimento, 20I2. (Arquivos Celso Furtado 5).

FURTADO, C. Obra autobiográfica. Edição definitiva. Coordenação de Rosa Freire D’Aguiar. São Paulo: Companhia das Letras, 20I4.

HYMER, S. The international operations of national firms: a study of direct foreign investments. Cambridge. MA: MIT Press, I976

KAY, C. As contribuições latino-americanas para a teoria crítica do desenvolvimento. Cad. CRH, Salvador, 3I, dezembro 20I8, p. 45I-46I.

LOVE, J. Economic ideas and ideologies in Latin America since I930. In: BETHEL, L. Ideas and ideologies in 2oth century Latin America. Cambridge: Cambridge University Press, I996.

LOVE, J. A construção do Terceiro Mundo: teorias do subdesenvolvimento na Romênia e no Brasil. Rio de Janeiro: Paz e Terra, I998.

MALLORQUIN, C. Celso Furtado: um retrato intelectual. Tradução de Célia Regina Barbosa Ramos. São Paulo: Xamã/Contraponto, 2005.

MELLO, J. M. O capitalismo tardio: contribuição à revisão crítica da formação e desenvolvimento da economia brasileira. Campinas. Tese (Doutorado). Instituto de Filosofia e Ciências Humanas, Universidade Estadual de Campinas, I975.

MANTEGA, G. Economia política brasileira. 8. ed. Petrópolis: Vozes, I984.

OLIVEIRA, F. A navegação venturosa: ensaios sobre Celso Furtado. São Paulo: Boitempo Editorial, 2003.

PALMA, G. Dependency: a formal theory of underdevelopment or a methodology for the analysis of concrete situations of underdevelopment?. World Development, Elsevier, 6, I978, p. 88I-924

PRADO JR., C. A revolução brasileira. São Paulo: Brasiliense, I966.

SAMPAIO JR., P. A. Entre a nação e barbárie: os dilemas do capitalismo dependente. Petrópolis: Vozes, I999.

SILVA, I. P. A teoria da dependência de Celso Furtado. II8 p. Dissertação (Mestrado em Economia). Programa de Pós-Graduação em Economia, Universidade Federal do Rio Grande do Sul, 2020.

SZMRECSÁNYI, T. Celso Furtado. Estudos Avançados, São Paulo, v. I5, n. 43, 200I, p. 347-362.

TAVARES, M. da C.; SERRA, J. (I97I). Além da estagnação: uma discussão sobre o estilo de desenvolvimento recente. In: BIELSCHOWSKY, R. Cinquenta anos de pensamento na Cepal. Rio de Janeiro: Record, 2000. 